\title{
First visceral leishmaniasis focus in Argentina
}

\author{
OD Salomon $/{ }^{+}$, A Sinagra ${ }^{1}$, MC Nevot ${ }^{2}$, G Barberian ${ }^{3}$, P Paulin ${ }^{3}$, JO Estevez ${ }^{2}$, Adelina Riarte ${ }^{1}$, \\ J Estevez ${ }^{4}$
}

Centro Nacional de Diagnóstico e Investigación en Endemo-Epidemias, CENDIE- ANLIS, Ministerio de Salud de la Nación, Av. Paseo Colón 568, 1263 Buenos Aires, Argentina IInstituto Nacional de Parasitología Dr Mario Fatala Chaben, ANLIS, Ministerio de Salud de la Nación, Argentina ${ }^{2}$ Veterinaria del Oeste, Posadas, Misiones, Argentina ${ }^{3}$ Hospital de Pediatría Dr J.P.Garrahan, Ciudad Autónoma de Buenos Aires, Argentina ${ }^{4}$ Ministerio de Salud Publica, Dirección Epidemiología, Misiones, Argentina

An eight-year old boy from Posadas $\left(27^{\circ} 23^{\prime} S\right.$, $\left.55^{\circ} 54^{\prime} \mathrm{W}\right)$ was diagnosed with visceral leishmaniasis $(V L)$ during 2006. Lutzomyia longipalpis was discovered in the backyard of his house, while the spread of canine visceral leishmaniasis was confirmed in Posadas. This is the southernmost report of a VL transmission focus and the first in Argentina.

Key words: visceral leishmaniais - Lutzomyia longipalpis - Argentina - canine visceral leishmaniasis

Visceral leishmaniasis (VL) is the most severe form of leishmaniasis. In Latin America VL is caused by the parasite Leishmania (L.) chagasi, commonly found on the domestic dog (Canis familiaris) and the main vector, the phlebotomine sand fly Lutzomyia longipalpis. Argentina reported 14 human leishmaniasis cases with visceral involvement from 1925 to 1989 . These cases were interspersed within the endemic area of tegumentary leishmaniasis (TL) due to Leishmania (V.) braziliensis. However, Lu. longipalpis was only found in 1951 and 2000 in Candelaria and Corpus respectively, in the province of Misiones (MI), without records of VL cases. Taking into account the lack of a parasite specific diagnosis and the absence of the usual vectors two hypotheses were suggested: a) VL in Argentina was due to visceralization of L. (V.) braziliensis, b) $L$. (L.). chagasi remained in enzootic foci where human contact is very unusual (Salomon et al. 2001). Afterward, Leishmania amazonensis and Leishmania guyanensis were also isolated from Argentinean TL human cases (Marco et al. 2005). L. amazonensis can disseminate from the cutaneous ulcers to produce atypical visceral leishmaniasis with hepatitis and lymphadenopathy (Aleixo et al. 2006). However, the risk of VL transmission changed when Paraguay reported an autochthonous human case during 2000 in Asunción, just across the border with Clorinda city, Formosa, Argentina. From 2000 until 2006, the Program of Leishmaniasis of Paraguay recorded 126 cases of human VL (66 only in 2006), 90.1\% from Asunción and the nearest Department of Central, while none of them were from the Eastern border with the Argentinian MI. Paraguay also reported a high proportion of VL-infected dogs in the same departments of the human cases, and confirmed the presence

+ Corresponding autor: odanielsalomon@gmail.com

Received 11 October 2007

Accepted 11 February 2008 of $L$. (L) chagasi and its vector $L u$. longipalpis (Canese 2000, Cousiño 2006, B Cousiño, unpublished observation). Therefore, intensified surveillance in Argentina was focused on the border area and migrant population. Two imported cases were then reported (Nocito et al. 2002, Martin-Sanchez et al. 2004), and Lu. longipalpis was found in December 2004, in Clorinda city (Salomon \& Orellano 2005).

In May 2006, an eight-year old boy from Posadas, MI, Argentina, was admitted to the National Paediatric Hospital Dr JP Garrahan. Leukemia was formerly suspected because of the following symptoms that had begun six weeks before the admission: fever, weight loss, hepatosplenomegaly and pancytopenia. Previously, he was a healthy boy. Chemotherapy was started with corticoids, etoposide and cyclosporin with an insufficient response. Three months later, symptoms returned with fever, chills, hepatomegaly, a bigger splenomegaly, and pancytopenia. After a second bone marrow biopsy, VL was diagnosed at the National Institute of Parasitology. Leishmania parasites were detected in bone marrow smears and cultures, the serology was reactive when tested for rK39 (InBios International, Seattle, USA), and the polymerase chain reaction performed with specific primers for Leishmania were positive, but negative with primers for L. braziliensis complex (C Pravia, unpublished observation). Serological and parasitological tests for Chagas disease were negative. Parasites in the bone marrow smears were confirmed again by the Hospital M. Muñiz (T Orduna, unpublished observation). Once diagnosed, the child was treated with antimonial compounds with a good haematological and clinical response. Because of elevated amylase, liposomal amphotericin was started at a daily $3 \mathrm{mg} / \mathrm{k}$ dose, for a course of 21 days and produced a very good outcome. Interviews with the child and his mother revealed that the family lived in the city of Posadas and the child only made weekend trips to two farms in Candelaria, both localities in MI.

Canine visceral leishmaniasis (CVL) was then actively searched among dogs in the house of the human case, other houses of Posadas city and outskirts (a ca- 
nine shelter), and around the places visited by the case in Martires. The dogs were analyzed for clinical symptoms of CVL, and skin and lymph nodes samples were taken for parasite isolation and parasitological diagnosis from any suspected case. The dogs were chararterized as polisymptomatic or oligosymptomatic (Table I) (Ministério da Saúde 2003, Alvar et al. 2004). Twenty out of 27 dogs studied showed clinical features of CVL; parasitological diagnosis was performed in 13 animals (65\%) and parasite isolation (3 out of $9 \mathrm{dogs}$ ). Specific serology for Leishmania donovani complex was also performed with rK39 recombinant antigen dipsticks (Table I) (Badaró et al. 1996, Scalone et al. 2002).

Phlebotomine sand fly captures were performed with a CDC light minitrap from 17:00 to 8:00 $\mathrm{h}$ two nights, on June 14th and 16th 2006, in four stations (Table II): Posadas ( 3 sites in the house of the VL human case,
3 sites in the canine shelter), Candelaria (3 sites) and the Martires Farm 1 and 2 ( 3 sites in each farm). Among 1956 sand flies of nine species collected, Lu. longipalpis was the only species captured in the backyard of the human patient, with a trap located in a wired chicken house below a papaya tree besides a water tank, $7 \mathrm{~m}$ from the house ( $\left.27^{\circ} 23^{\prime} 00^{\prime} \mathrm{S}, 55^{\circ} 54^{\prime} 19^{\prime} \mathrm{W}\right)$. In Candelaria village, in the "Center for Wild Animal Reahablitation and

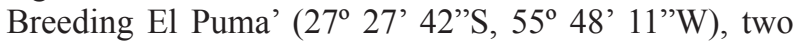
$\mathrm{Lu}$. longipalpis were captured with a trap in the cage of monkeys (Cebus apella), but a single Lutzomyia neivai was recovered from the cage of the canidae Chrysocyon brachyurus. On the other hand, in Martires, in the farms where the case used to sleep during the year prior to the onset of the symptoms $\left(27^{\circ} 26^{\prime} \mathrm{S}, 55^{\circ} 24^{\prime} \mathrm{W}\right)$, sand flies of eight species different from $\mathrm{Lu}$. longipalpis were captured. The relative abundance and sex ratio of the species

TABLE I

Main features of canine visceral leishmaniasis in animals from Posadas, Misiones, Argentina, 2006

\begin{tabular}{|c|c|c|c|c|c|c|c|}
\hline Dogs & Clinical features $^{\mathrm{a}}$ & Smears & Tissue samples & Serological test rK39 & Culture & Isolation & Residence \\
\hline 1 & $\mathrm{O}$ & + & Skin & + & - & & Posadas \\
\hline 3 & $\mathrm{P}$ & + & Lymph node & + & - & & Posadas \\
\hline 4 & $\mathrm{P}$ & + & Lymph node & + & ND & & Posadas \\
\hline 6 & $\mathrm{O}$ & + & Lymph node & + & - & & Posadas \\
\hline 7 & $\mathrm{P}$ & + & Skin/Lymph node & + & + & + & Posadas \\
\hline 8 & $\mathrm{P}$ & + & Skin/Spleen & + & - & & Posadas \\
\hline 14 & $\mathrm{P}$ & + & Skin & ND & - & & Posadas \\
\hline 15 & $\mathrm{O}$ & + & Skin & + & ND & & Posadas \\
\hline 16 & $\mathrm{P}$ & + & Skin/Lymph node & + & + & + & Shelter \\
\hline 17 & $\mathrm{P}$ & + & Lymph node & + & ND & & Shelter \\
\hline 18 & $\mathrm{P}$ & + & Skin & + & - & & Shelter \\
\hline 19 & $\mathrm{P}$ & + & Skin/Lymph node & + & ND & & Shelter \\
\hline 25 & $\mathrm{O}$ & + & Skin/Lymph node/Spleen & + & + & + & Posadas \\
\hline
\end{tabular}

a: oligosymptomatic (O) - dogs with local skin lesions, alopecia and exfoliative dermatitis, and lymphadenopathy; polisymptomatic (P) - dogs were with severe skin lesions (alopecy and exfoliative dermatitis, furfuraceous eczema, ulcerative dermatitis, hyperkeratosis), lymphadenopathy, onychogryphosis, weigth loss, cachexia, keratoconjunctivitis and splenomegaly, keratoconjunctivitis and splenomegaly; ND: not done.

TABLE II

Phlebotomine sand flies captured with a CDC light minitrap by species, gender (male/female), and station in three localities in the province of Misiones, Argentina, on 14th and 16th June 2006

\begin{tabular}{|c|c|c|c|c|c|}
\hline & \multicolumn{2}{|c|}{ Posadas } & \multirow{2}{*}{$\begin{array}{c}\text { Candelaria } \\
\text { wild refuge }\end{array}$} & \multicolumn{2}{|c|}{ Martires } \\
\hline & patient-house & dog refuge & & farm 1 & farm 2 \\
\hline Lu. longipalpis & $4 / 24$ & 0 & $0 / 2$ & 0 & 0 \\
\hline Lu. neivai & 0 & 0 & $1 / 0$ & $85 / 38$ & $976 / 678$ \\
\hline Lu. migonei & 0 & 0 & 0 & $1 / 4$ & $33 / 41$ \\
\hline Lu. fischeri & 0 & 0 & 0 & $0 / 2$ & $5 / 10$ \\
\hline Lu. shannoni & 0 & 0 & 0 & 0 & $8 / 5$ \\
\hline Lu. whitmani & 0 & 0 & 0 & 0 & $8 / 12$ \\
\hline Lu. pessoai & 0 & 0 & 0 & 0 & $0 / 3$ \\
\hline Lu quinquefer & 0 & 0 & 0 & 0 & $1 / 0$ \\
\hline Lu. monticola & 0 & 0 & 0 & 0 & $1 / 0$ \\
\hline
\end{tabular}


found in Martires were consistent with other collections made in MI (Salomon et al. 2002, 2006). The highest captures were obtained in pigsties less than $20 \mathrm{~m}$ from the houses (80.0-98.8\% of the sand flies). Lutyzomyia monticola was reported for the first time since 1948 in Argentina, when a single capture was recorded in Montecarlo, MI (26 34' S, 54 $47^{\circ} \mathrm{W}$ ) (Bejarano \& Duret 1950).

A retrospective search of suspected cases was performed in Posadas hospitals in June 2006. The suspected case definition was a person resident in Posadas that attended any local hospital with a fever together with one or more of the following symptoms without etiological diagnosis: splenomegaly, hepatomegaly, lymphadenitis and weight loss. After house interviews of the suspected cases, all were discarded but one that was not found due to inconsistencies in the address records (PW Orellano, unpublished observation).

The antecedents of the VL case, the dogs born and living in Posadas and infected with Leishmania, and the Lu. longipalpis captures in the backyard of the VL case house, indicate that this is the southernmost and the first autochthonous focus of VL ever reported in Argentina. The canine and entomological data associated with the human case close the VL chain transmission and support the conclusion that the urban Posadas perimeter is the most potential site of VL transmission. Lu. longipalpis seems to be already dispersed in Posadas and closer localities. Mosquito trapping not designed for phlebotomine surveillance captured $23 \mathrm{Lu}$. longipalpis in Corpus, MI, during 2000-2001 (Salomon et al. 2001), and four males (August 2001- June 2003) in the outskirts of Posadas, close to the dog shelter (G Rossi, unpublished observation). Unfortunately, the presence of VL vectors around Posadas was not reported to the National Surveillance System, despite the alarm and request after the onset of VL in Paraguay (Salomon et al. 2001, Salomon \& Orellano 2005). The presence of canine VL usually precedes the increase of human cases and after this study, about 820 dogs were diagnosed with CVL in Posadas (MC Nevot, unpublished observation). Therefore, the risk of human VL in Posadas and surroundings areas was stated and surveillance measures should be settled as soon as possible. After the case reported in this paper and up to December 2007 there were nine further LV human cases diagnosed from Posadas. In January and September 2007 three cases were reported each month, two adults and one child, while in July, August (a fatal case of four months old) and October, one infected child was diagnosed by month. All the adults with symptomatic VL were homeless alcoholics, and the children lived in different neighbourhoods. The study of the current status of the focus including natural infection of vectors and Leishmania species identification is in progress.

\section{REFERENCES}

Aleixo JA, Nascimento ET, Monteiro GR, Fernandes MZ, Ramos AMO, Wilson ME, Pearson D, Jeronimo SMB 2006. Atypical American visceral leishmaniasis caused by disseminated Leishmania amazonensis infection presenting with hepatitis and adenopathy. Trans R Soc Trop Med Hyg 100: 79-82.

Alvar J, Cañavate C, Molina R, Moreno J, Neto J 2004. Canine Leishmaniasis. Adv Parasitol 57: 1-88.

Badaró R, Benson DR, Eulálio MC, Freire M, Cunha S, Netto EM, Pedral-Sampaio D, Madureira C, Burns JM, Houghton RL, David JR, Reed SG 1996. rK39: A cloned antigen of L. chagasi that predicts active visceral leishmaniasis (VL). J Infect Dis 173: 758-761.

Bejarano JFR, Duret JP 1950. Contribución al conocimiento de los flebótomos argentinos (Diptera, Psychodidae). Rev San Mil Arg 49: $327-336$

Canese A 2000. Leishmaniosis visceral canina en el área metropolitana de la "Gran Asunción", Paraguay 2000. Medicina (B Aires) 60 (Supl III): 65.

Cousiño B 2006. Vigilancia y Control de la Leishmaniasis en el Paraguay. In Organización Panamericana de la Salud (ed.), Informe Final de la Reunión de Expertos OPS/OMS sobre Leishmaniasis Visceral en las Américas, Panaftosa, Rio de Janeiro, Brazil, p. 34-36.

Marco JD, Barroso PA, Calvopina M, Kumazawa H, Furuya M, Korenaga $\mathrm{M}$, Cajal SP, Mora $\mathrm{MC}$, Rea MM, Borda CE, Basombrio MA, Taranto NJ, Hashiguchi Y 2005. Species assignation of Leishmania from human and canine american tegumentary leishmaniasis cases by multilocus enzyme electrophoresis in North Argentina. Am J Trop Med Hyg 72: 606-611.

Martin-Sanchez J, Navarro-Mari JM, Pasquau-Liano J, Salomon OD, Morillas-Marquez F 2004. Visceral Leishmaniasis caused by Leishmania infantum in a Spanish patient in Argentina: What is the origin of the infection? Case Report. BMC Infectious Diseases 4: 20.

Ministério da Saúde 2003. Manual de Vigilancia e controle da Leishmaniose Visceral. Secretaria de Vigilância em Saúde, Departamento de Vigilância Epidemiológica, Brasília, Brazil.

Nocito I, Serra E, Montero A 2002 . Visceral involvement due to Leishmania mexicana in a patient with acquired immunodeficiency syndrome. Am J Med 113: 260-262.

Salomon OD, Orellano PW 2005. Lutzomyia longipalpis in Clorinda, Formosa province, an área of potential visceral leishmaniasis transmission in Argentina. Mem Inst Oswaldo Cruz 100: 475-476.

Salomon OD, Orellano PW, Quintana MG, Pérez S, Sosa Estani S, Acardi S, Lamfri M 2006. Transmisión de la leishmaniasis tegumentaria en Argentina. Medicina (B Aires) 66: 211-219.

Salomon OD, Rossi G, Sosa Estani S, Spinelli G 2001. Presencia de Lutzomyia longipalpis y situación de la leishmaniosis visceral en Argentina. Medicina (B Aires) 61: 174-118.

Salomon OD, Rossi GC, Spinelli GR 2002. Ecological aspects of phelobotomine (Diptera, Psychodidae) in an endemic area of tegumentary leishmaniasis in the Northeastern Argentina, 19931998. Mem Inst Oswaldo Cruz 97: 163-168.

Scalone A, De Luna R, Oliva G, Baldi L, Satta G, Vesco G, Mignone W, Turilli C, Mondesire R, Simpson D, Donoghue A, Frank G, Gradoni L 2002. Evaluation of the Leishmania recombinant k39 antigens as a diagnostic marker for canine leishmaniasis and validation of a standardized enzyme-linked inmunosorbent assay. Vet Parasitol 104: 275-285. 